\title{
EFEITO DE DOSES DE HERBICIDA E TIPOS DE INOCULANTES SOB A SOJA FTS PARAGOMINAS NO BREJO PARAIBANO
}

Rayan Sabino Reges ${ }^{1}$, Allan Jônathan do Nascimento Lino $^{1}$, João Paulo de Oliveira Santos ${ }^{2}$, Mateus Costa Batista ${ }^{3}$, José Luiz Carneiro da Silva ${ }^{1}$, Leossávio César de Souza ${ }^{1}$

${ }^{1}$ Universidade Federal da Paraíba - UFPB, curso de Agronomia, PB. ${ }^{2}$ Universidade Federal Rural de Pernambuco UFRPE, Pós-Graduação em Engenharia Ambiental, PE. ${ }^{3}$ Universidade Federal de Campina Grande - UFCG, PósGraduação em Engenharia Agrícola, PB . E-mail: rayanreges14@gmail.com

\section{RESUMO}

As áreas cultivadas com soja (Glycine max L. Merrill) no Brasil vem crescendo a cada ano, sendo esse grão responsável por expressivos resultados econômicos no setor agrícola. Resultados que levam a cultura a se expandir por novas áreas no território nacional, no entanto, essa expansão requer estudos de manejo para essas novas condições e cultivares. Assim, o presente trabalho objetiva avaliar os efeitos da inoculação e de doses de herbicida sob as características agronômicas e de produção da cultivar de soja FTS Paragominas no município de Areia, Paraíba. O delineamento experimental foi constituído em um fatorial $2 \times 3+1$, conduzido em blocos casualizados, com quatro repetições, totalizando 28 parcelas. As unidades experimentais foram constituídas de três linhas de $3 \mathrm{~m}$, espaçadas em $0,50 \mathrm{~m}$. A área útil foi formada pela linha central, onde foram coletados os dados referentes às características avaliadas: altura da planta $(\mathrm{cm})$, altura de inserção da primeira vagem $(\mathrm{cm})$, número de vagens por planta, número de semente por vagem, peso de mil sementes (g) e produtividade $\left(\mathrm{kg} \mathrm{ha}^{-1}\right)$. As médias foram avaliadas através do teste de Tukey a $5 \%$ de probabilidade. Foi encontrado efeito significativo a $1 \%$ de probabilidade do inoculante sob a altura de plantas, e a $5 \%$ sob o número de vagens por planta. Para a interação inoculante $\times$ glifosato, encontrouse efeito significativo a $1 \%$ para as variáveis altura de plantas e produtividade. A utilização de inoculante líquido associado com a dose de $3 \mathrm{~L}$ ha ${ }^{-1}$ de glifosato mostrou-se satisfatória na altura de planta, no número de vagens por planta e na produtividade, obtendo-se resultados semelhante a registrada em experimentos com bons resultados para soja.

Palavras-chave: fixação biológica de nitrogênio; glifosato; Glycine max. .

\section{EFFECT OF HERBICIDE DOSES AND TYPES OF INOCULANTS UNDER SOYBEAN FTS PARAGOMINAS IN REGION OF THE BREJO, STATE OF PARAÍBA}

\begin{abstract}
The areas planted with soybeans (Glycine max L. Merrill) in Brazil have been growing every year, being this grain responsible for significant economic results in the agricultural sector. Results that lead the culture to expand to new areas in the national territory, however, this expansion requires management studies for these new conditions and cultivars. Thus, the present study aims to evaluate the effects of inoculation and herbicide doses under the agronomic and production characteristics of the soybean cultivar FTS Paragominas in the city of Areia, Paraíba. The experimental design consisted of a $2 \times 3+1$ factorial, conducted in randomized blocks, with four replications, totaling 28 plots. The experimental units were composed of three $3 \mathrm{~m}$ lines, spaced $0.50 \mathrm{~m}$ apart. The useful area was formed by the center line, where data were collected on the evaluated characteristics: plant height $(\mathrm{cm})$, height of first pod insertion $(\mathrm{cm})$, number of pods per plant, number of seeds per pod, weight of pods thousand seeds $(\mathrm{g})$ and productivity (kg ha-1). The averages were evaluated using the Tukey test at $5 \%$ probability. Significant effect was found at $1 \%$ probability of the inoculant under the height of plants, and at $5 \%$ under the number of pods per plant. For the inoculant $\times$ glyphosate interaction, a significant effect was found at $1 \%$ for plant height and productivity variables. The use of liquid inoculant associated with the dose of $3 \mathrm{~L}$ ha- 1 of glyphosate was satisfactory at plant height, number of pods per plant and productivity, obtaining results similar to those recorded in experiments with good results for soybean.
\end{abstract}

Key words: biological fixation of nitrogen; glyphosate; Glycine max. 


\section{INTRODUÇÃO}

A soja (Glycine max L. Merrill) é uma leguminosa de origem chinesa, cujo início do cultivo data de cerca de cinco mil anos atrás, sendo seus antecedentes mais antigos encontrados nas áreas úmidas e baixas dos vales da China Central. Sua proliferação como cultura alimentar na Ásia se deu a aproximadamente três mil anos, de onde se espalhou pelo mundo. Do ponto de vista de grandes cultivos comerciais, foi no início do século $X X$ que passou a ser cultivada com esse fim nos Estados Unidos, desencadeando a partir daí um rápido aumento da produção e os primeiros esforços para o desenvolvimento de cultivares com melhores características de adaptação e produtividade (EMBRAPA, 2001).

No Brasil a soja representa um dos pilares do agronegócio, obtendo-se nas últimas décadas crescimentos expressivos no quantitativo produzido. Resultados que estão atrelados a diversos fatores, dentre os quais: boa capacidade de inserção no mercado internacional, principalmente pelo comércio de produtos do complexo agroindustrial da soja; consolidação do grão como fonte de proteína vegetal, o que propicia o atendimento da demanda pelos seguimentos que trabalham com a produção de produtos de origem animal; geração e oferta de tecnologias, que permitiram que a cultura se expandisse para as diversas regiões do globo (HIRAKURI; LAZZAROTO, 2014).

Do ponto de vista agronômico, a soja é uma cultura que requer altos suprimentos de nitrogênio, o que se deve em grande parte ao alto teor de proteínas em seus grãos, que pode chegar até a $40 \%$. Para cada tonelada de grãos produzida, são necessários em torno de $80 \mathrm{~kg}$ de nitrogênio, que é oriundo a partir da mineralização da matéria orgânica no solo, e principalmente por meio da fixação biológica de nitrogênio (FBN), reconhecidamente realizada por bactérias do gênero Bradyhizobium, responsáveis por retirar o $\mathrm{N}_{2}$ atmosférico e o reduzir à forma amoniacal nos nódulos radiculares, no qual é translocado e posteriormente convertido a aminoácidos e proteínas (NOGUEIRA; HUNGRIA, 2014).

Essas bactérias são adicionadas ao solo por meio de inoculantes, que em sua maioria são encontrados em duas principais formas comerciais, os inoculantes líquidos e o inoculantes turfosos. A utilização destes é imprescindível ao produtor, visto trazerem uma economia substancial pela não utilização de adubos minerais nitrogenados, além de que para a planta garantem o incremento necessário no fornecimento de nitrogênio, melhorando assim os teores de proteínas nos grãos, a produtividade, o aumento de matéria seca nos restos culturais e auxiliam na cobertura natural do solo (PASTORE, 2016).

No tocante ao manejo da cultura da soja, merece atenção especial o controle de plantas daninhas, visto a enormidade de problemas que essas plantas podem trazer, que vão desde a redução de produtividade até a complicações na hora da colheita. Logo o uso de herbicidas se faz necessário, buscando-se a minimização desses agentes infestantes. No entanto, mesmo após a realização de todas as medidas para controlar as plantas daninhas, podem ser verificados prejuízos da ordem de 5 a $25 \%$ no rendimento dos cultivos. O que se deve ao manejo incorreto dos defensivos utilizados, principalmente quanto à quantidade e época de aplicação empregada (VIDAL et al., 2011).

No Nordeste brasileiro, notadamente nos estados com pouca ou nenhuma tradição com a cultura da soja, torna-se necessário o desenvolvimento de trabalhos que contemplem estudos com essa cultura, principalmente quanto à adaptabilidade de cultivares e estratégias de manejo produtivo. Nesse contexto, o presente trabalho objetiva avaliar os efeitos da inoculação e de doses de herbicida sob as características agronômicas e de produção da soja FTS Paragominas no município de Areia, Paraíba.

\section{MATERIAL E MÉTODOS}

$O$ experimento foi instalado em condições de campo no período de maio a setembro de 2017, na área experimental de Chã de jardim, pertencente ao Centro de Ciências Agrárias - CCA da Universidade Federal da Paraíba - UFPB, Campus II, localizada no município de Areia sob as coordenadas 06응 $57^{\prime} 48^{\prime \prime}$ de latitude Sul e 350 $41^{\prime} 30^{\prime \prime}$ de longitude Oeste do meridiano de Greenwich e altitude de $618 \mathrm{~m}$. O município integra a Microrregião Geográfica Brejo Paraibano, apresentando

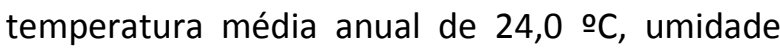
relativa média em torno de $80 \%$ e precipitação média anual de $1400 \mathrm{~mm}$ (COSTA et al., 2011).

As sementes da cultivar FTS Paragominas foram submetidas a duas formas de inoculação, onde para partes destas utilizou-se inoculante líquido e a outra parte inoculante tufoso. Para os 
tratamentos que utilizaram o inoculante turfoso, as sementes foram inoculadas utilizando 0 Nordofix turfa, a base de Bradyrhizobium japonicum, na proporção de $0,160 \mathrm{~kg}$ de inoculante para $50 \mathrm{~kg}$ de semente para 0 primeiro plantio. As sementes foram umedecidas com uma solução açucarada a $10 \%$ na proporção de $300 \mathrm{ml}$ para $50 \mathrm{~kg}$ de sementes, adicionandose posteriormente 0 inoculante. Para os tratamentos que utilizaram o inoculante líquido, usou-se o inoculante Nordofix gel a base de Bradyrhizobium japonicum na proporção de 100 $\mathrm{ml}$ para $50 \mathrm{~kg}$ de sementes.

A semeadura foi realizada em maio de 2017. Após o preparo do solo com limpeza da área, escarificarão e abertura dos sucos, as sementes foram semeadas de forma manual, a uma profundidade de $3 \mathrm{~cm}$ e cobertas com o próprio solo, obedecendo um espaçamento de $0,5 \mathrm{~m}$ entre linhas, sendo colocadas 40 sementes por metro linear, após 30 dias foi realizado o desbaste deixando-se 20 plantas por metro linear.

A adubação química foi realizada manualmente de acordo com as necessidades de adubação observadas na análise química do solo (Tabela 1), realizada no Laboratório de Solos do Departamento de Solos e Engenharia Rural (DSER) da UFPB/CCA. Sendo assim, foram adicionados na área $60 \mathrm{~kg} \mathrm{ha}^{-1}$ de $\mathrm{P}_{2} \mathrm{O}_{5}$ na forma de superfosfato simples e $50 \mathrm{~K}_{2} \mathrm{O} \mathrm{kg} \mathrm{ha}{ }^{-1}$ na forma de cloreto de potássio, sendo estes aplicados na fundação. Não se fez adubação nitrogenada consequentemente pelo propósito do trabalho.

Tabela 1. Resultado das análises do solo (0-20 cm de profundidade) da área experimental. CCA/UFPB, Areia - Paraíba, 2013.

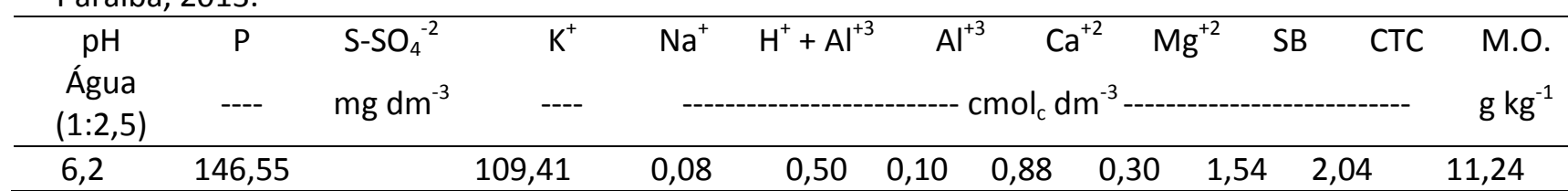

Fonte: Laboratório de Solos - CCA/UFPB.

SB: Soma de Base Trocáveis

CTC: Capacidade de Troca de Catiônica

M.O.: Matéria Orgânica - Walkley - Black

Após 21 dias da semeadura, para o controle das plantas daninhas, aplicaram-se as dosagens do herbicida glifosato nos respectivos tratamentos, obedecendo-se as recomendações mínimas e máximas do fabricante, que variam de 0,5 a $6,0 \mathrm{~L} \mathrm{ha}$. Assim os tratamentos foram divididos em três dosagens, a dose I: $0,5 \mathrm{~L} \mathrm{ha}^{-1}$, dose II: 3,0 L ha-1 e dose III: 6,0 L ha ${ }^{-1}$.

$$
\text { Utilizou-se um delineamento }
$$
experimental de blocos ao acaso em esquema fatorial 2 (Inoculante líquido; inoculante turfoso) $\times 3$ (Dose 1: 0,5 L ha ${ }^{-1}$, dose 2: 3,0 L ha ${ }^{-1}$ e dose 3: $\left.6,0 \mathrm{Lha}^{-1}\right)+1$ (Testemunha) e quatro repetições totalizando 28 parcelas. Cada bloco teve uma testemunha, sem aplicação de glifosato nem utilização de inoculante. As unidades experimentais foram constituídas de três linhas de $3 \mathrm{~m}$, espaçadas em $0,50 \mathrm{~m}$. A área útil foi formada pela linha central.

Apesar de ter sido instalado durante o período chuvoso da região, nos quatro meses de experimento, a ocorrência de chuvas se deu de forma irregular. Registraram-se precipitações abaixo da média climatológica, com um total
P, K, Na: Extrator Mehlich 1

$\mathrm{H}+\mathrm{Al}$ : Extrator Acetato de Cálcio 0,5 M, $\mathrm{pH} 7,0$

$\mathrm{Al}, \mathrm{Ca}, \mathrm{Mg}$ : Extrator $\mathrm{KCl} 1 \mathrm{M}$

acumulado no período de $149,6 \mathrm{~mm}$. Sendo 21,4 $\mathrm{mm}$ em maio, $100,8 \mathrm{~mm}$ em junho, 20,4 mm em julho e $7 \mathrm{~mm}$ em agosto.

A colheita foi realizada quando as plantas alcançaram o estádio de desenvolvimento R8, ou seja, quando $95 \%$ das vagens apresentaram a coloração típica de vagem madura. Em seguida as vagens foram debulhadas manualmente, limpas com auxílio de peneiras, e postas para secar em condições naturais, acondicionadas em sacos de papel Kraft.

O comportamento da cultivar FTS Paragominas foi avaliado por meio de amostragens utilizando-se uma amostra aleatória de quatro plantas por parcela. A altura de plantas foi avaliada por meio de uma régua, que foi disposta ao lado da planta, sendo obtido o valor em $\mathrm{cm}$ do solo até o ápice. A inserção da primeira vagem foi mensurada em $\mathrm{cm}$ por meio de uma régua aferida que foi disposta ao lado da planta, sendo obtido o valor do solo até a primeira vagem. Contou-se o número de vagens em cada planta selecionada, levando em conta apenas 
àqueles viáveis (as que apresentarem sementes dentro das vagens).

Para a massa de mil sementes, estas foram levadas para o Laboratório de Sementes do CCA/UFPB, onde se procedeu a contagem e separação, sendo posteriormente pesadas em balança de precisão. Para a determinação da produtividade, as sementes foram pesadas com e sem a presença da vagem, sendo os resultados obtidos transformados para $\mathrm{kg} \mathrm{ha} \mathrm{a}^{-1}$.

Os dados foram submetidos à análise de variância, pelo teste $F$, e as médias dos tratamentos, quando significativas, foram comparadas pelo teste de Tukey $5 \%$ de probabilidade de erro. Todas as análises foram realizadas utilizando-se o programa computacional Assistat versão 7.6 beta (SILVA, 2013).

\section{RESULTADOS E DISCUSSÃO}

Estão apresentados na Tabela 2 os resumos da análise de variância para as características avaliadas, bem como os seus respectivos coeficientes de variação. Observou-se efeito significativo a $1 \%$ de probabilidade, pelo Teste $F$, do inoculante sob a altura de plantas (ALP) e a $5 \%$ sob o número de vagens por planta (NVP). Para a interação inoculante $\times$ glifosato, verificou-se efeito significativo a $1 \%$ para as variáveis altura de plantas (ALP) e produtividade (PDT).

Tabela 2. Resumo das análises de variâncias, referentes aos dados de Altura da Inserção de Vagem (AIV), Altura de Plantas (ALP), Número de Vagens por Planta (NVP), Número de Sementes por Vagem (NSV), Massa de Mil Sementes (MMS) e Produtividade (PDT) de plantas de soja FTS Paragominas. Areia - Paraíba, 2018.

\begin{tabular}{|c|c|c|c|c|c|c|c|}
\hline \multirow{2}{*}{ Fontes de variação } & \multirow{2}{*}{ Gl } & \multicolumn{6}{|c|}{ Quadrados médios } \\
\hline & & AIV & ALP & NVP & NSV & MMS & PDT \\
\hline Blocos & 3 & $1,368^{\mathrm{ns}}$ & $4,659^{\text {ns }}$ & $360,3^{\text {ns }}$ & $0,017^{\text {ns }}$ & $391,2^{\text {ns }}$ & $1068564,2^{\mathrm{ns}}$ \\
\hline Inoculantes (INO) & 1 & $0,094^{\mathrm{ns}}$ & $71,760^{* *}$ & $2223,4^{*}$ & $0,024^{\mathrm{ns}}$ & $1961,5^{\mathrm{ns}}$ & $37600,6^{\text {ns }}$ \\
\hline Glifosato (GLI) & 2 & $1,929^{\text {ns }}$ & $5,542^{\text {ns }}$ & $401,3^{\text {ns }}$ & $0,001^{\mathrm{ns}}$ & $2672,0^{\mathrm{ns}}$ & $1262542,2^{\mathrm{ns}}$ \\
\hline Interação (INO×GLI) & 2 & $4,929^{\text {ns }}$ & $69,042^{* *}$ & $872,7^{\text {ns }}$ & $0,023^{\text {ns }}$ & $201,2^{\text {ns }}$ & $3487092,3^{* *}$ \\
\hline Resíduo & 19 & 1,681 & 7,862 & 500,1 & 0,052 & 471,9 & 511148,6 \\
\hline Total & 27 & - & - & - & - & - & \\
\hline C.V. (\%) & - & 12,65 & 8,67 & 51,98 & 13,0 & 14,44 & 35,61 \\
\hline \multicolumn{8}{|c|}{$\begin{array}{l}\text { ns, }{ }^{* *} \text { e : não significativo e significativo a } 1 \text { e } 5 \% \text { de probabilidade pelo teste } F \text {, respectivamente, C.V. - coeficiente } \\
\text { de variação. Gl - grau de liberdade. }\end{array}$} \\
\hline $\begin{array}{l}\text { Apesar de } \\
\text { estatisticamente, a } \\
\text { testemunha foi maior } \\
\text { tratamentos com inocu } \\
\text { herbicidas. A associação } \\
\text { dose de } 3 \mathrm{~L} \mathrm{ha}^{-1} \text { de glifo } \\
\text { os melhores resulta }\end{array}$ & $\begin{array}{l}\text { não } \\
\text { dia d } \\
\text { que as } \\
\text { tes tur } \\
\text { inocula } \\
\text { o foi a c } \\
\text { s, se }\end{array}$ & $\begin{array}{l}\text { dif } \\
\text { a altur } \\
\text { oriunda } \\
\text { fosos e } \\
\text { ante líqu } \\
\text { que apre } \\
\text { ndo su }\end{array}$ & $\begin{array}{r}\text { rirem } \\
\text { da } \\
\text { dos } \\
\text { de de } \\
\text { o e a } \\
\text { entou } \\
\text { erior }\end{array}$ & \multicolumn{4}{|c|}{$\begin{array}{l}\text { expresse um bom desenvolvimento vegetativo da } \\
\text { planta, esse parâmetro pode levar a um } \\
\text { acamamento com maior facilidade evento que } \\
\text { pode comprometer a colheita (SHERRIE et al., } \\
\text { 2011). No entanto, diante dos resultados desse } \\
\text { experimento, a altura média de plantas foi bem } \\
\text { inferior à altura adequada para a colheita } \\
\text { (MATSUO et al., 2015). }\end{array}$} \\
\hline
\end{tabular}


Figura 1. Médias da Altura de Planta (ALT) em função da dosagem de herbicida e tipo de inoculante para plantas de soja FTS Paragominas. Areia - Paraíba, 2017.

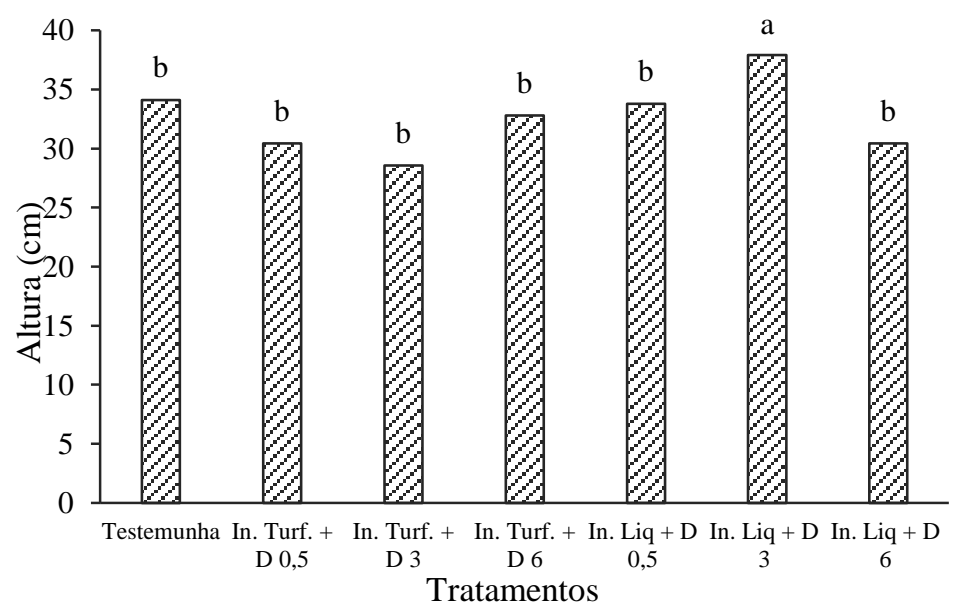

In. Liq.: Inoculante Líquido; In. Turf.: Inoculante Turfoso; D: Doses; $0,5 \mathrm{~L} \mathrm{ha}^{-1} ; 3 \mathrm{~L} \mathrm{ha}^{-1} ; 6 \mathrm{~L} \mathrm{ha}^{-1}$.

Médias seguidas da mesma letra na coluna não diferem estatisticamente entre si pelo teste de Tukey.

Borges et al. (2017) em um sistema de semeadura direta, onde se aplicou uma dosagem de glifosato de $2,5 \mathrm{~L} \mathrm{ha}^{-1}$ e utilizou-se a inoculação via mistura líquida, obteve resultados para altura de planta de $75 \mathrm{~cm}$. Resultados bem superiores aos encontrados nesse trabalho, todavia, deve-se considerar que os referidos autores também utilizaram nutrição mineral nitrogenada, mesmo que baixa na semeadura, além de adubação foliar, o que possivelmente contribuiu para esses resultados.

O NVP da testemunha foi bastante inferior ao observado nos demais tratamentos, embora seja estatisticamente igual a alguns dos tratamentos que utilizaram inoculantes turfosos associados a herbicidas. Os melhores valores, assim como observados para ALP, foram observados no tratamento inoculante líquido +3 litros $\mathrm{ha}^{-1}$ de glifosato, com média de 69,93 vagens (Figura 2), valor bem superior ao observado por Santana et al. (2011), onde com esse mesmo tipo de inoculante obteve uma média de 29,5 vagens planta ${ }^{-1}$. Esse alto valor pode estar associado também a redução significativa de plantas daninhas devido a dosagem aplicada de glifosato, o que propicia uma menor competição por nutrientes e consequente maior disponibilidade, o que influencia no melhor desenvolvimento da soja. Embora seja uma variável importante, não necessariamente um alto número de vagens significa uma alta produção, uma vez que isso é dependente da quantidade de grãos por vagem, bem como por suas boas condições.

Figura 2. Número de Vagens por Planta (NVP) em função da dosagem de herbicida e tipo de inoculante para plantas de soja FTS Paragominas. Areia - Paraíba, 2018.

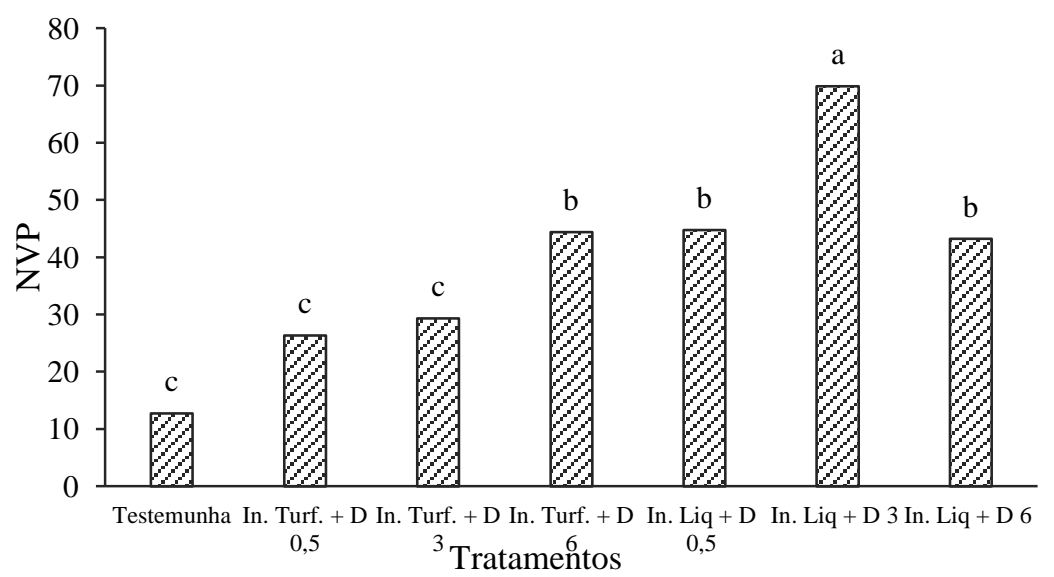

In. Liq.: Inoculante Líquido; In. Turf.: Inoculante Turfoso; D: Doses; $0,5 \mathrm{~L} \mathrm{ha}^{-1} ; 3 \mathrm{~L} \mathrm{ha}^{-1} ; 6 \mathrm{~L} \mathrm{ha}^{-1}$.

Médias seguidas da mesma letra na coluna não diferem estatisticamente entre si pelo teste de Tukey. 
Para a altura de inserção da primeira vagem, embora não se tenha obtido diferença estatística, devem-se levar em consideração as baixas médias encontradas $(8,75$ a $12,75 \mathrm{~cm})$. Esse parâmetro é muito importante, uma vez que é determinante para a regulagem da altura da barra de corte da colhedora, permitindo a máxima eficiência durante esse procedimento (MAUAD et al., 2010). Para a cultura da soja, os padrões normais para altura de corte na colheita mecanizada são de $0,15 \mathrm{~m}$ (PEREIRA JÚNIOR et al., 2010).

O número de sementes por vagem $(1,58$ a 1,84) também não apresentou diferença estatística entre os tratamentos, sendo os resultados inferiores ao encontrados por Silva et al. (2011), onde encontrou-se média de 2,24 grãos por vagem em cultivar de soja tratada com inoculante líquido na semeadura. No tocante a produção, essa variável é uma das que apresenta menor variação entre as diversas situações de cultivo, fruto dos trabalhos de melhoramento genético vegetal, que são responsáveis por propiciar plantas com média de dois grãos por vagem (MUNDSTOCK; THOMAS, 2005).

Os resultados da massa de mil grãos para todos os tratamentos $(129,41$ a $163,79 \mathrm{~g})$ foram semelhantes aos verificados por Procópio et al. (2015a), para a FTS Paragominas cultivada no agreste de Sergipe, onde obteve-se média de $159,8 \mathrm{~g}$.

A associação entre o inoculante líquido e a dosagem de $3 \mathrm{~L}$ também foi a mais satisfatória entre os tratamentos, quando levada em consideração a produtividade da FTS Paragominas, sendo obtida uma média de 3.055 $\mathrm{kg} \mathrm{ha}{ }^{-1}$ (Tabela 2). Valores superiores ao observados por Procópio et al. (2015a), no agreste sergipano, que utilizou inoculante turfoso e plantio no fim da estação chuvosa, e para a mesma cultivar obtiveram produtividade média de $2.418 \mathrm{~kg} \mathrm{ha}{ }^{-1}$. Os mesmos autores em experimento semelhante, porém utilizando diferentes doses de adubação nitrogenada, obtiveram uma produtividade média de $3.567 \mathrm{~kg}$ ha ${ }^{-1}$ para a dose de $10 \mathrm{~kg} \mathrm{ha}^{-1}$ de N (PROCÓPIO et al., 2015b). Embora nesse estudo se tenha constatado a interação de doses de glifosato e inoculantes, alguns trabalhos não verificaram a influência isolada do herbicida sob a produtividade da soja, Guimarães et al. (2012) por exemplo, observaram que seus resultados de produção não foram influenciados por esses defensivos, obtendo médias superiores a 3.000 $\mathrm{kg} \mathrm{ha}{ }^{-1}$, o que classificou como um ótimo resultado.

Tabela 3. Médias da Produtividade (PDT) de plantas de soja FTS Paragominas. Areia - Paraíba, 2018.

\begin{tabular}{lc}
\hline & Médias \\
\cline { 2 - 2 } & PDT (kg ha $\left.{ }^{-1}\right)$ \\
\hline Testemunha & $1572,5 \mathrm{~b}$ \\
In. Turf. + D 0,5 & $1046 \mathrm{~b}$ \\
In. Turf. + D 3 & $1547 \mathrm{~b}$ \\
In. Turf. + D 6 & $2049,5 \mathrm{~b}$ \\
In. Liq + D 0,5 & $2472,5 \mathrm{a}$ \\
In. Liq + D 3 & $3055 \mathrm{a}$ \\
In. Liq + D 6 & $1877 \mathrm{~b}$ \\
\hline
\end{tabular}

In. Liq.: Inoculante Líquido; In. Turf.: Inoculante Turfoso

D: Doses; $0,5 \mathrm{~L} \mathrm{ha}^{-1} ; 3 \mathrm{~L} \mathrm{ha}^{-1} ; 6 \mathrm{~L} \mathrm{ha}^{-1}$.

Médias seguidas da mesma letra na coluna não diferem estatisticamente entre si pelo teste de Tukey.

Deve-se destacar a superioridade dos resultados aqui obtidos com o inoculante líquido, visto que boa parte da literatura indica os inoculantes turfosos como sendo o meio mais propício para o bom desempenho do rizóbio, uma vez que a turfa possui alto teor de matéria orgânica, representando assim uma considerável fonte de nutrientes (HUNGRIA et al., 2007) e proteção física para essas bactérias no solo (LUPWAYI et al., 2006).
Todavia, observa-se uma tendência crescente de uso de inoculantes líquidos, que facilitam o processo em campo, sendo preferíveis por parte do agricultor devido as facilidades no tratamento da semente, além de representar um menor desgaste das máquinas. Porém, os resultados oriundos do uso desse tipo de inoculante são dependentes das moléculas protetoras dos rizóbios presentes nas formulações. E diferente das turfas que oferecem 
uma destacável proteção física e nutricional ao rizóbio, essas novas formulações podem não serem tão eficientes nesse quesito, sendo preciso testes mais aprofundados quanto a sua compatibilidade com fungicidas e micronutrientes. Apesar dessas questões, devese levar em consideração que os inoculantes líquidos apresentam grande facilidade de esterilização do meio de cultura onde os rizóbio irão se desenvolver, evitando-se a contaminação por agentes externos. Dessa forma é possível obter um maior número de células de rizóbios no produto e na semente, o que potencialmente favorece sua utilização e a obtenção de bons resultados (HUNGRIA et al., 2007).

É reconhecido que o estresse advindo da deficiência hídrica determina a ocorrência de plantas de soja pouco desenvolvidas, apresentando baixa altura, reduzida área foliar e entrenós curtos. A nível metabólico é responsável por uma série de alterações, como a redução do potencial hídrico foliar, o fechamento estomático, a diminuição da taxa fotossintética, a redução da sua parte aérea, a aceleração da senescência, abscisão das folhas, dentre outras (FERRARI et al., 2015). Soma-se a esse cenário, o fato de que sob altas temperaturas e baixa umidade do solo, os rizóbios inoculados podem vi a perder a sua viabilidade (COSTA, 1996). Logo, os resultados desse trabalho foram potencialmente influenciados pela escassez de chuva durante a sua execução, o que afetou negativamente os dados obtidos. Deve-se ressaltar que a precipitação acumulada no período de experimento foi de 149, $6 \mathrm{~mm}$, bem inferior ao que é requerido pela soja, que necessita de 450 a $800 \mathrm{~mm}$ em seu ciclo para a máxima expressão das suas características produtivas (FARIAS et al., 2007).

\section{CONCLUSÕES}

As irregularidades pluviométricas comprometeram a máxima expressão dos resultados das variáveis analisadas, visto a precipitação acumulada na área de estudo ter sido inferior ao requerido pela cultura, sendo pertinentes novos testes em condições mais favoráveis.

A utilização de inoculante líquido associado com a dose de $3 \mathrm{~L} \mathrm{ha}^{-1}$ de glifosato mostrou-se satisfatória para as características altura de planta, número de vagens por planta e produtividade.

\section{REFERÊNCIAS}

BORGES, W. L. B.; MATEUS, G. P.; FREITAS, R. S.; HIPÓLITO, J. L.; CAZENTINI FILHO, G.; TOKUDA, F. S.; CASTELETI, M. L.; ASPARINO, A. C.; TOMAZINI, N. R.; BÁRBARO-TORNELI, I. M. Sistemas sustentáveis de produção de soja no Noroeste Paulista. Revista Nucleus, ed. esp., p. 83-92, 2017. https://doi.org/10.3738/1982.2278.2823

COSTA, J. A. Cultura da soja. Porto Alegre: Evangraf, 1996. 233p.

COSTA, T. S. A.; COSTA FILHO, J. F.; BARACHO, D. C.; SANTOS, T. S.; MARINHO, E. C. S. Análise da temperatura do ar em Areia - PB, em anos de ocorrênciade "El Niño". In: CONGRESSO BRASILEIRO DE AGROMETEOROLOGIA, 17., 2011, Guarapari. Anais... Guarapari. CBA, 2011.

EMBRAPA, Empresa Brasileira de Pesquisa Agropecuária. Tecnologias de produção de soja Região Central do Brasil-2001/2002. Embrapa Soja-Documentos (INFOTECA-E), 2001.

FARIAS, J.R.B.; NEPOMUCENO, A.L.; NEUMAIER, N. Ecofisiologia da soja. Londrina: Embrapa Soja, (Embrapa Soja. Circular técnica, 48), 2007. 9p.

FERRARI, E.; PAZ, A.; SILVA, A. C. Déficit hídrico no metabolismo da soja em semeaduras antecipadas no Mato Grosso. Nativa, v. 3, n. 1, p. 67-77, 2015. https://doi.org/10.14583/2318-7670.v03n01a12

GUIMARÃES, V. F.; HOLLMANN, M. J.; FIOREZE, S. L.; ECHER, M. M.; COSTA, A. C. P. R.; ANDREOTTI, $M$. Produtividade e qualidade de sementes de soja em função de estádios de dessecação e herbicidas. Planta Daninha, v. 30 , n. 3, p. 567573, 2012. http://dx.doi.org/10.1590/S010083582012000300012.

HIRAKURI, M. H.; LAZZAROTTO, J. J. O agronegócio da soja nos contextos mundial e brasileiro. Embrapa, 2014. (Documentos, n.10)

HUNGRIA, M.; CAMPO, R. J.; MENDES, I. C. A importância do Processo de fixação biológica de nitrogênio para a cultura da soja: componente essencial para a competitividade do produto brasileiro. Londrina: Embrapa Soja, 2007.

LUPWAYI, N. Z.; CLAYTON, G. W.; RICE, W. A. Rhizobial inoculants for legume crops. Journal of 
Crop Improvement, v. 15, n. 2, p. 289-231, 2006. https://doi.org/10.1300/J411v15n02 09

MATSUO, E.; FERREIRA, S. C.; SEDIYAMA, T. Botânica e Fenologia. In: SEDIYAMA, T.; SILVA, F.; BORÉM, A. (Ed.) Soja: do plantio à colheita. Viçosa: UFV, 2015. p. 27-53.

MAUAD, M; SILVA, T. L. B.; ALMEIDA NETO, A. I.; ABREU, V. G. Influência da densidade de semeadura sobre características agronômicas na cultura da soja. Revista Agrarian, v. 3, n. 9, p. 175-181, 2010. https://doi.org/10.30612/agrarian.v3i9.7

MUNDSTOCK, C. M.; THOMAS, A. L. Soja: fatores que afetam o crescimento e o rendimento dos grãos. Porto Alegre: UFRGS, 2005. 31p.

NOGUEIRA, M. A.; HUNGRIA, M. Boas Práticas de Inoculação em Soja. In: ROSA, A. P. S. A; OLIVEIRA, A. C. B. (Eds.) Atas e Resumos. Pelotas: Embrapa Clima Temperado, 2014. p. 40-45.

PASTORE, A. Manejo de inoculação com Bradyrhizobium em soja associado ao tratamento fitossanitário das sementes. 2016. $42 f$. Dissertação (Mestrado em Tecnologias de Bioprodutos Agroindustriais) Universidade Federal do Paraná, Palotina, 2016.

PEREIRA JÚNIOR, P.; REZENDE, P. M.; MALFITANO, S. C.; LIMA, R. K.; CORRÊA, L. V. T.; CARVALHO, E. R. Efeito de doses de silício sobre a produtividade e características agronômicas da soja [Glycine max (L.)]. Ciência e Agrotecnologia, v.34, p.908-913, 2010. http://dx.doi.org/10.1590/S141370542010000400016 .

PROCÓPIO, S. O.; CARVALHO, H. W. L.; BALBINOT JUNIOR, A. A. Épocas de semeadura no desempenho da cultura da soja no agreste nordestino. In: CONGRESSO BRASILEIRO DE SOJA, 7., 2015, Florianópolis. Anais... Florianópolis: EMBRAPA, 2015a.

PROCÓPIO, S. O.; CARVALHO, H. W. L.; MOREIRA, A.; BALBINOT JUNIOR, A. A. Arranjo de plantas e adubação nitrogenada foliar na cultura da soja cultivada no agreste nordestino. In: CONGRESSO BRASILEIRO DE SOJA, 7., 2015, Florianópolis. Anais... Florianópolis: EMBRAPA, 2015b.
SANTANA, M. J.; SOUSA, F. C. A.; SILVEIRA, A. L. SILVA, C. A. Aplicação de cobalto, molibdênio e inoculante na cultura da soja (Glycine max L. Merrill). Global Science and Technology, v. 4, n. 2, p.01-08, 2011.

SHERRIE, I.; KHALED, O.; WASHINGTON, E.; LAGE, P.; WOODS, S.; KANTARTZI, S. K.; MEKSEM, K.; LIGHTFOOT, D. A.; KASSEM, M. A. Evaluation of Several Agronomic Traits in 'Essex'By 'Forrest' Recombinant Inbred Line Population of Soybean [Glycine max (L.) Merr.]. Atlas Journal of Plant Biology, v. 1, n. 1, p. 13- 17, 2011. https://doi.org/10.5147/ajpb.2011.0030.

SILVA, A. F.; SCHONINGER, E. L.; MONTEIRO, S.; CAIONE, G.; CARVALHO, M. A. C.; DALCHIAVON, F. C.; NOETZOLD, R. Inoculação com bradyrhizobium e formas de aplicação de cobalto e molibdênio na cultura da soja. Revista Agrarian, v. 4, n. 12, p. 98-104, 2011. https://doi.org/10.30612/agrarian.v4i12.829

SILVA, F. A. S. ASSISTAT: versão 7.6 beta. 2013. Disponível em: <Available at: http://www.assistat.com/>. Acesso em: dez. 2017.

VIDAL, R. A.; MEROTTO A. J. R.; TREZZI, M. M.; SCHWEIG, A.; CIESLIK, L. F. Desvendada a causa do prejuízo das infestantes nas culturas. Revista Plantio Direto, n. 121, p. 29-32, 2011.

Recebido para publicação em 22/03/2018 Revisado em 03/07/2018 Aceito em 04/07/2018 